\section{SETTING THE INDUSTRY STANDARD}

With over 20 years' experience in UK dentistry Software of Excellence has both the knowledge and expertise to provide proven digital imaging solutions and does so through EXAMINE ${ }^{\text {PRO }}$.

EXAMINE ${ }^{\text {PRO }}$ places all images, including X-rays, jpegs and intra-oral images, into a single database, regardless of the digital imaging hardware used to create the original. This seamless integration enables dental professionals to access all images from the patient's file with the click of a mouse.

Software of Excellence's digital imaging solutions set the industry

\section{REUPHOLSTERY ON SITE}

Meditelle-Dental, the specialist seating manufacturers based in Birmingham, are now offering dental practices an onsite service to re-upholster your patient seating.

Whatever the type or brand of patient chair you have, and whatever its condition, Meditelle can restore it to its former glory. Their expert upholsterers use the highest standards of traditional skills backed by the latest technology to carry out a full onsite re-upholstery of your dental equipment.

Meditelle's onsite re-covering service ensures that your equipment will not be out of service for any length of time with all processes carried out in the practice with minimal fuss.

Ensuring the safety of your equipment such as patient chairs or even operator chairs is vital. Re-upholstering may be all that's required if you have any scratch marks or slits in your chair vinyl covering that present a serious infection control hazard. Treating this quickly and efficiently with Meditelle's re-covering service limits the chances of infections and keeps your equipment safe and hygienic.

To find out more about this service visit www.meditelle-dental.co.uk or for a quote call 01213321850. standard for high quality imaging, with quick and easy transmission to your computer screen. Using EXACT and EXAMINE ${ }^{\text {PRO }}$ means new images are automatically added to the patient chart, ensuring you always have the latest restorative information as well as the location and age of all films and images to hand.

EXAMINE $^{\text {PRO }}$ provides the ability to import pictures and digital images into a patient's treatment plan, presentation, or attach these images to an email making the preparation of patient presentations easier than ever before.

\section{TOOTHACHE GEL HAS NEW LOOK}

The range of products that includes top selling toothache gel, Orajel Dental Gel, has been relaunched with bold, colourful new packaging. The restyled range allows patients to quickly and easily identify which variant is most suitable for their needs so they can relieve toothache when symptoms appear. Orajel Dental Gel and Orajel Extra Strength Gel are now available in striking deep red packets. The Extra Strength variant, which contains the maximum level of benzocaine available without prescription in the Orajel range, includes bright yellow design elements making a clear difference between the two products.

Orajel variants contain benzocaine, a powerful local anaesthetic that works by temporarily blocking the pathway
For more information about Software of Excellence's digital imaging solutions call 08452600461 or visit www.soeidental.com.

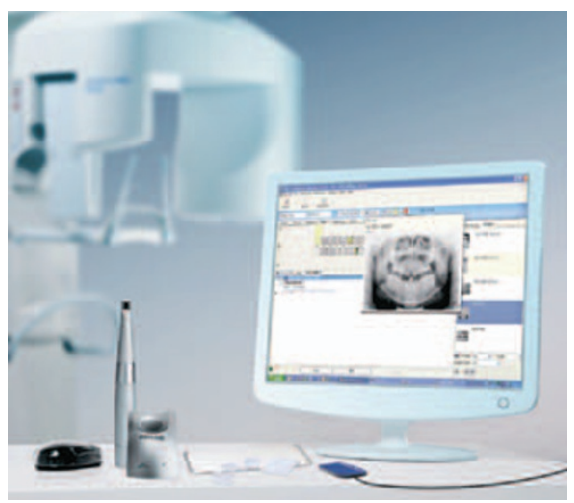

of pain signals along the nerves and relieves pain by numbing the area.

The gel form of Orajel products gives control over the product during application and goes right to the source of the pain to provide effective targeted relief. A dentist should be consulted if the toothache persists.

Orajel Dental Gel and Orajel Mouth Gel are available from pharmacists and all major retailers. Orajel Extra Strength Gel is a P product and is available in pharmacies.

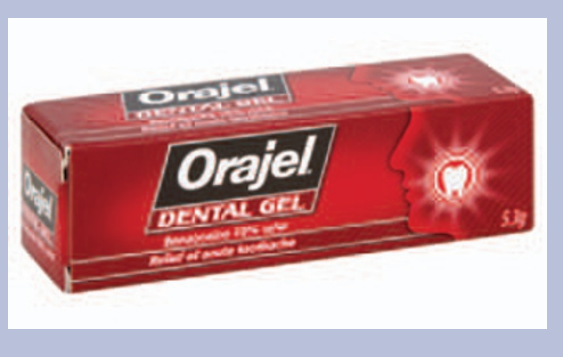

\section{CROWNING GLORY SHARED WITH CUSTOMERS}

To help celebrate 35 years as a leading supplier of dental restorations, CosTech Elite is supplying ZirconArch crowns and bridges at a price of just $£ 35$ each to all of their customers throughout April 2012.

Presenting a perfect balance between strength and aesthetics, ZirconArch crowns and bridges from CosTech Elite provide patients with a beautiful restoration that is truly built to last. Produced entirely in ceramic, ZirconArch restorations offer superior colouration and subtle translucency to standard porcelain fused to metal implants, and CosTech Elite technicians can perfectly match the shade of the patient's existing teeth for a seamless, natural appearance.

ZirconArch crowns and bridges also provide excellent biocompatibility, and with CosTech Elite's impression technology, offer a perfect gum fit.

For further information call 01474 320 076, Email info@costech.co.uk or visit www.costech.co.uk. 